\title{
Current problems in the use of organic UV filters to protect skin from excessive sun exposure
}

\author{
Zuzana Klimová, Jarmila Hojerová, Silvia Pažoureková \\ Institute of Biotechnology and Food Science, Faculty of Chemical and Food Technology, \\ Slovak University of Technology, Radlinského 9, 81237 Bratislava, Slovak Republic \\ zuzana.klimova@stuba.sk
}

\begin{abstract}
The evidences of the harmful effects of skin exposure to excessive UltraViolet (UV) radiation, primarily on the development of skin cancer, have increased over the last decade. Therefore, national and international health authorities have encouraged the public to take protective sunscreens, and respectively also everyday cosmetics containing UV filters. In these products, a mixture of the UV filters, including both inorganic and organic nature, has been shown to be more effective than the individual UV filter. However, currently there are concerns about the safety and actual effectiveness of some UV filters; especially about certain UV-absorbing compounds (organic UV filters). Three cardinal problems are the most questionable. First, that certain UV filters are absorbed through the skin resulting in systemic exposure with unknown consequences. Second, that certain UV filters show the potential to be adversely endocrine disruptors. Third, that certain UV filters are partially degraded by UV radiation, what making them photounstable and unable to fulfil their basic protective function. The purpose of this article is to discuss these problems.
\end{abstract}

Keywords: sunscreens, organic UV filters, endocrine disruptors, dermal absorption, photostability, safety

\section{Introduction}

Exposure of the human body to sunlight especially during the summer and holidays, as well as exposure to UltraViolet (UV) light at any time during the year, became fashionable. Solar radiation on the Earth's surface consists inter alia of shorter UVB radiation in the wavelength range $280-315 \mathrm{~nm}$ and longer UVA radiation (315-400 nm; SCCS, 2012). With the exception of certain beneficial effects, both components of UV radiation have several adverse consequences in humans. UVB radiation causes the inflammation of the skin (sunburn) and the resulting reddening of the skin (erythema). UVA radiation is the main cause of premature aging of the skin system (EC, 2006). Scientific findings also suggest that excessive exposure to UVB radiation, as well as UVA radiation adversely affects the body's immune system. But the worst manifestation of excessive exposure to UV radiation is the development of skin cancer. A direct link between the carcinogenic action and sunlight radiation has been confirmed and the International Agency for Research on Cancer (IARC) has classified solar radiation, UVB and also UVA as human carcinogens (EC, 2006). Therefore national and international health authorities have urged the public to take protective measures, among these to use sunscreen products.

\section{Sunscreen products}

Sunscreen products (sunscreens) marketed in the European Union (EU) are considered cosmetic products (cosmetics; EC, 2006), but for example in the United States they are considered Over-theCounter (i.e. non-prescription) drug products (FDA, 2011). The term "sunscreen product" in EU means any preparation (such as creams, oils, gels, sprays) intended to be placed in contact with the human skin with a view exclusively or mainly to protecting it from UV radiation by absorbing, scattering or reflecting radiation (EC, 2006). The main role of sunscreens is to promote natural skin photoprotective mechanisms (formation of melanin, thickening of stratum corneum, sweating, making certain substances in the skin), to allow a reasonable extension of stay in the sun without causing acute, and chronic changes due to UV radiation (Hojerová and Boskovičová, 2009). Sunscreen products should be sufficiently effective against UVB and UVA radiation to ensure a high protection of public health. The effectiveness of sunscreen product against UVB radiation is evaluated as Sun Protection Factor (SPF) and against UVA as Protection Factor (UVA-PF), both measured in laboratory by using in vitro or in vivo methods. The SPF number is measured as a numerical ratio between a minimal erythemal dose (MED) of skin protected with sunscreen, applied in the amount of $2 \mathrm{mg} / \mathrm{cm}^{2}$ and a MED value of unprotected skin (EC, 2006). Scientific findings show that certain biological damage to the skin can be prevented and reduced if the UVA-PF (measured in the persistent pigment darkening test) is at least $1 / 3$ of the SPF (EC, 2006).

\section{Ultraviolet filters}

UV filters are active substances exclusively or mainly intended to protect the skin against certain UV radia- 
tion (EC, 2009). They can be classified into organic (chemical) and inorganic (physical) on the basis of their mechanism of action. At present, 26 organic and 1 inorganic (Titanium Dioxide) UV filters are allowed in cosmetics sold in EU (Tab. 1) within the limits and under the conditions regulated by the cosmetic legislation (EC, 2009). Second inorganic compound (Zinc Oxide), which is sometimes used in sunscreens, is regulated primarily as a cosmetic pigment (EC, 2009). Organic UV filters absorb UV radiation with excitation to a higher energy state. Excess energy is dissipated by emission of higher

Tab. 1. List of permitted UV filters which cosmetic products may contain according to the current EU legislation (EC, 2009).

\begin{tabular}{|c|c|c|c|c|}
\hline $\begin{array}{c}\text { EC } \\
\text { Number }^{\mathrm{a}}\end{array}$ & Chemical Name & INCI Name & CAS Number & $\mathbf{C}_{\max }(\%)^{\mathrm{b}}$ \\
\hline 1 & 4-Aminobenzoic acid & PABA & $150-13-0$ & 5 \\
\hline 2 & $\begin{array}{l}\text { N,N,N-Trimethyl-4-(2-oxoborn- } \\
\text { 3-ylidenemethyl) anilinium methyl sulphate }\end{array}$ & $\begin{array}{l}\text { Camphor Benz- } \\
\text { alkonium Methosulfate }\end{array}$ & $52793-97-2$ & 6 \\
\hline 3 & 3,3,5-Trimethylcyclohexylsalicylate & Homosalate & $118-56-9$ & 10 \\
\hline 4 & 2-Hydroxy-4-methoxy benzophenone & Benzophenone-3 & $131-57-7$ & 10 \\
\hline 6 & $\begin{array}{l}\text { 2-Phenylbenzimidazole-5-sulphonic acid and its } \\
\text { potassium, sodium and triethanolamine salts }\end{array}$ & $\begin{array}{l}\text { Phenylbenzimidazole } \\
\text { Sulfonic Acid }\end{array}$ & 27503-81-7 & $\begin{array}{c}8 \\
\text { (as acid) }\end{array}$ \\
\hline 7 & $\begin{array}{l}\text { 3,3'-(1,4-Phenylenedimethylene)bis( } 7,7 \text {-dimethyl- } \\
\text { 2-oxobicyclo-( } 2,2,1) \text { hept-1-ylmethane sulfonic acid } \\
\text { and its salts }\end{array}$ & $\begin{array}{l}\text { Terephthalylidene } \\
\text { Dicamhor Sulfonic } \\
\text { Acid }\end{array}$ & $92761-26-7$ & $\begin{array}{c}10 \\
\text { (as acid) }\end{array}$ \\
\hline 8 & 4-tert-Butyl-4'-methoxydibenzoylmethane & $\begin{array}{l}\text { Butyl Methoxy- } \\
\text { dibenzoylmethane }\end{array}$ & 70356-09 & 5 \\
\hline 9 & $\begin{array}{l}\alpha \text {-(2-Oxoborn-3-ylidene)-toluene-4-sulphonic acid } \\
\text { and her salts }\end{array}$ & $\begin{array}{l}\text { Benzylidene Camphor } \\
\text { Sulfonic Acid }\end{array}$ & $56039-58-8$ & $\begin{array}{c}6 \\
\text { (as acid) }\end{array}$ \\
\hline 10 & 2-Cyano-3,3-diphenyl acrylic acid, 2-ethylhexyl ester & Octocrylene & $6197-30-41$ & $\begin{array}{c}10 \\
\text { (as acid) }\end{array}$ \\
\hline 11 & $\begin{array}{l}\text { Polymer of } \mathrm{N}-\{(2 \text { and } 4) \text {-[2-oxoborn-3-ylidene }) \\
\text { methyl]benzyl }\} \text { acrylamide }\end{array}$ & $\begin{array}{l}\text { Polyacrylamidomethyl } \\
\text { Benzylidene Camphor }\end{array}$ & $113783-61-2$ & 6 \\
\hline 12 & 2-Ethylhexyl 4-methoxycinnamate & $\begin{array}{l}\text { Ethylhexyl } \\
\text { Methoxycinnamate }\end{array}$ & $5466-77-3$ & 10 \\
\hline 13 & Ethoxylated ethyl 4-aminobenzoate & PEG-25 PABA & $116242-27-4$ & 10 \\
\hline 14 & Isoamyl-4-methoxycinnamate & $\begin{array}{l}\text { Isoamyl } \\
\text { p-methoxycinnamate }\end{array}$ & $71617-10-2$ & 10 \\
\hline 15 & $\begin{array}{l}\text { 2,4,6-Trianilino-( } p \text {-carbo-2'-ethylhexyl-1'oxi)- } \\
\text { 1,3,5-triazine }\end{array}$ & Ethylhexyl Triazone & 88122-99-0 & 5 \\
\hline 16 & $\begin{array}{l}\text { 2-(2H-benzotriazol-2-yl)-4-methyl-6-(2-methyl- } \\
\text { 3-(1,3,3,3-tetramethyl-1-(trimethylsilyl)oxy)- } \\
\text { disiloxanyl)propyl) phenol }\end{array}$ & $\begin{array}{l}\text { Drometrizole } \\
\text { Trisiloxane }\end{array}$ & $155633-54-8$ & 15 \\
\hline 17 & $\begin{array}{l}\text { 4, 4-[[(6-[[[(1,1-dimethylethyl)amino }] \\
\text { carbonyl }] \text { phenyl }] \text { amino }] 1,3,5 \text {-triazine- } \\
\text { 2,4-dyl }] \text { diimino }] \text { bis-, bis-(2-ethylhexyl) benzoate }\end{array}$ & $\begin{array}{l}\text { Diethylhexyl Butamido } \\
\text { triazone }\end{array}$ & $154702-15-5$ & 10 \\
\hline 18 & 3-(4'-Methylbenzylidene) camphor & $\begin{array}{l}\text { 4-Methylbenylidene } \\
\text { Camphor }\end{array}$ & $38102-62-4$ & 4 \\
\hline 19 & 3-Benzylidene camphor & $\begin{array}{l}\text { 3-Benzylidene } \\
\text { Camphor }\end{array}$ & $15087-24-8$ & 2 \\
\hline 20 & 2-Ethylhexyl salicylate & Ethylhexyl Salicylate & $118-60-5$ & 5 \\
\hline 21 & 4-Ethylhexyl 4-dimethylaminobenzoate & $\begin{array}{l}\text { Ethylhexyl Dimethyl } \\
\text { PABA }\end{array}$ & 21245-02-3 & 8 \\
\hline 22 & $\begin{array}{l}\text { 2-Hydroxy-4-methoxybenzophenone- } \\
\text { 5-sulfonic acid and its sodium salt }\end{array}$ & Benzophenone-4 & $\begin{array}{l}4065-45-6 / 6628- \\
37-1\end{array}$ & $\begin{array}{c}5 \\
\text { (as acid) }\end{array}$ \\
\hline 23 & $\begin{array}{l}\text { 2,2'-Methylenebis-[4-(1,1,3,3- } \\
\text { tetramethylbutyl)-6-(2H benzotriazol-2-yl) phenol] }\end{array}$ & $\begin{array}{l}\text { Methylene Bis-benzo- } \\
\text { triazolyl Tetra-methyl- } \\
\text { butylphenol }\end{array}$ & $103597-45-1$ & 10 \\
\hline
\end{tabular}


Tab. 1. (continue) List of permitted UV filters which cosmetic products may contain according to the current EU legislation (EC, 2009).

\begin{tabular}{|c|c|c|c|c|}
\hline $\begin{array}{c}\text { EC } \\
\text { Number }^{\mathrm{a}}\end{array}$ & Chemical Name & INGI Name & CAS Number & $\mathbf{C}_{\max }(\%)^{b}$ \\
\hline 24 & $\begin{array}{l}\text { 2,2'-(1, 4-Phenylene)bis[1H-benzimidazole- } \\
\text { 4,6-disulfonic acid }]\end{array}$ & $\begin{array}{l}\text { Disodium Phenyl } \\
\text { Dibenzimidazole } \\
\text { Tetrasulfonate }\end{array}$ & $180898-37-7$ & $\begin{array}{c}10 \\
\text { (as acid) }\end{array}$ \\
\hline 25 & $\begin{array}{l}\text { 2,2'-[6-(4-methoxyphenyl)-1,3,5-triazine-2,4- } \\
\text { diyl]bis[5-(2-ethylhexyl)oxy] phenol }\end{array}$ & $\begin{array}{l}\text { Bis-ethylhexyloxy- } \\
\text { phenol Methoxyphenyl } \\
\text { Triazine }\end{array}$ & 187393-00-6 & 10 \\
\hline 26 & $\begin{array}{l}\text { Methyl 3-[4-[2,2-bis(ethoxycarbonyl)ethenyl] } \\
\text { phenoxy]propenyl dimethyl polysilogane }\end{array}$ & Polysilicone-15 & 207574-74-1 & 10 \\
\hline 27 & Titanium dioxide & Titanium Dioxide & $13463-67-7$ & 25 \\
\hline 28 & $\begin{array}{l}\text { 2-[-4-(diethylamino)-2-hydroxybenzoyl]-, } \\
\text { hexylester }\end{array}$ & $\begin{array}{l}\text { Diethylamino } \\
\text { Hydroxybenzoyl Hexyl } \\
\text { Benzoate }\end{array}$ & $302776-68-7$ & 10 \\
\hline
\end{tabular}

${ }^{\mathrm{a}}$ European Commission reference number,

${ }^{\mathrm{b}}$ Maximum authorized concentration in cosmetic products by European Commission (EC, 2009).

wavelengths or relaxation by photochemical processes, for example isomerisation and heat release. They include benzophenones, camphors, cinnamates, salicylates, triazines, among others (Table 1). Inorganic sunscreens, i.e. Titanium Dioxide and Zinc Oxide, protect the skin by reflecting and scattering UV radiation.

Depending on the ability to protect against the wavelength spectral range, there are UVA, UVB, and broad spectrum UV filters. Modern sunscreens should be containing a mix of UVB filters, because it has been shown to be more effective than the individual filter, as well as UVA filters. Besides UV filters, sunscreens may contain other additives which are also thought to play a role in protecting the skin from the effects of exposure to UV radiation (Klocker et al., 2012).

\section{Current problems in the use of UV filters}

Before each UV filter has been approved for the use in cosmetics, it has undergone a series of tests regarding its safety. However, some UV filters have already been on the market for decades and the safety tests were performed by the available analytical methods and knowledge. Nowadays, there is a growing concern regarding safety of some UV filters, mainly when they are applied on the skin with a variable condition. Among the most frequently discussed problems, there are indications that some UV filters could be:

1. absorbed through the skin resulting in systemic exposure with unknown consequences;

2. potential endocrine disruptors;

3. degraded by UV radiation, what making them photounstable and unable to fulfil their principal function.

\section{Adverse dermal absorption of some UV filters}

Dermal absorption process is a global term which describes the passage of compounds trough the skin. This process can be divided into three steps. The first step is penetration, what is the entry of a substance into a particular layer or structure such as an entry of a compound into the uppermost layer of the skin - the stratum corneum. The second step is permeation. It is penetration from one layer into another, which is both functionally and structurally different from the first layer. The third and the last step is resorption, the uptake of a substance into the vascular system (lymph and/or blood vessel), which acts as the central compartment (WHO, 2006; SCCS, 2012).

UV filters are designed for external application on the outermost layers of the skin. An ideal sunscreen should exhibit a high skin accumulation of UV filters in the stratum corneum, but the minimal permeation into the deeper part of the skin. However, recent studies have shown that some UV filters in certain formulation have the potential to be absorbed through the skin, further metabolized and eventually bioaccumulated and/or excreted (Chisvert et al., 2012). Therefore, photoprotection is lost and the skin becomes susceptible to sun damage (Durand et al., 2008). Furthermore, this absorption may result in various adverse health serious effects such as mutagenic or estrogenic (Ma et al., 2003; Schreus et al., 2005).

These observations that the human body can absorb some organic UV filters through the skin triggered researches to study their percutaneous absorption and excretion (Gonzalez et al., 2006; Giokas et al., 2007). But, despite the permitted 26 organic UV filters, attention is focused to only the most 
popular of them such as Benzophenone-3 (BP-3), 4-Methylbenzylidene Camphor (4-MBC), Octyl Methoxycinnamate (OMC), Octyl Salicylate (OS), and Butyl Metoxydibenzoylmethane (BMDBM) (Giokas et al., 2007).

The amounts of BP-3, OMC and OS recovered from tape-stripped stratum corneum demonstrate that these UV filters permeate into epidermis and have potential to be absorbed into deeper layer (Toutiou and Godin, 2008). Other research studies indicated the intact amount of BP-3 and its metabolite Benzophenone-1 (BP-1) in human urine after 4 hours dermal exposure to commercially available sunscreens (Felix et al., 1998). Also residues of OMC and BP-3 were detected in human breast milk samples (Hany and Nagel, 1995). The UV filter OMC is a very frequently used chemical in sunscreens and cosmetics worldwide. According to Janjua et al. (2004) and Schlumpf et al. (2008), OMC has also been found in the human blood, urine and milk samples of women, as a consequence of dermal application of OMC containing products.

Other studies indicate that UV filter BMDBM has also the potential to permeate into the skin, but its encapsulation into lipid microspheres may reduce percutaneous absorption, maintain efficiency and reduce possible toxicological hazard (Scalia et al., 2011).

\section{Potential estrogenic effects of some UV filters}

Currently, the potential of transdermal permeation is explored to certain types of UV filters which have particularly controversial properties - to cause potential adverse changes in the endocrine system of the body (Carou et al., 2009; Nashev et al., 2010; Lodén et al., 2011; Guldson et al., 2012), especially groups of benzophenones or camphor derivates. The so-called endocrine disrupting (ED) chemicals have been subject to intensive scientific investigation and discussion since the 1990s (SCCS, 2012). According to the current definition of the European Commission "A potential ED is an exogenous substance or mixture that possesses properties that might lead to endocrine disruption in an intact organism, or its progeny, or (sub) population" and "An ED is an exogenous substance or mixture that alters function(s) of the endocrine system and consequently causes adverse health effects in an intact organism, or its progeny, or (sub) population" (SCCS, 2012). The first mention regarding potential ED effects filters appeared nearly twenty years ago. In $2001 \mathrm{UV}$ filters were first discussed as potential ED, when Schlumpf et al. (2001) examined six frequently used UVA and UVB organic UV filters in sunscreens for estrogenicity. Their investigation revealed that $\mathrm{BP}-3$, OMC, 4-MBC displayed estro- genic effects in vitro and in vivo in mice. In the same year the Scientific Committee on Cosmetic and Non-Food Products (SCCNFP) issued an opinion on the matter and concluded that studies showed a number of important technical shortcomings (SCCS, 2012). However, since then the assessment of potential endocrine effects of UV filters has been the subject of many studies. The primary exposure of humans to UV filters is by cosmetics through dermal application. This means that UV filters enter the systemic circulation directly without first being metabolized by passage through the liver. For example, the estrogenic effect of $4-\mathrm{MBC}$ in rats was three-fold greater after topical application compared with oral exposure. The majority of the in vitro studies reported that $\mathrm{BP}-3,4-\mathrm{MBC}$ and $\mathrm{OMC}$ exhibit estrogenic activity (Schlumpf et al., 2001, 2008; Schreus et al., 2002; Kunisue et al., 2012). Not all of these UV filters had estrogenic effect in acute in vivo models (Schlumpf et al., 2001; Schreurs et al., 2002). In summary, the SCCNFP based on in vitro tests confirmed the weak estrogenic activity of some UV filters but SCCNFP also emphasized that the in vitro potency of studied organic UV filters studied was considerably lower than the one observed for the positive control (17 $\beta$-estradiol). An endocrine activity of some organic UV filters was also very low in comparison with exposure to known estrogenic substances for example in food, and steroids used in hormonal therapy (SCCS, 2012). But the idea of monitoring these properties of UV filters is probably justifiable considering that UV filters are presented also in other cosmetic products which we use every day and frequently.

\section{Potential photounstability of some UV filters}

As a consequence of the light absorption, organic UV filters may undergo predominantly changes in their molecular configuration, or may be transformed into different chemically reactive molecules. Hence there is a need to investigate specific phototoxic effects, such as photoirritancy, photosensitisation and photomutagenicity (SCCS, 2012).

The photostability of UV filters in sunscreen is an important consideration in their development and subsequent performance as these filters are designed to absorb UV light. The term photostability means resistance to permanent structural and functional changes under the influence of solar energy. Several recent studies show that some of UV filters using in sunscreen products are photounstable, especially regarding the protection against UVA radiation spectrum (Hojerová et al., 2011; Lodén et al., 2011)

A high SPF label indicates for customers a longterm photoprotection. This is guaranteed only if 
all contained UV filters are photostable throughout the sunlight exposure, or their metabolites have comparable protective effect. Thus, the production of photostable products is extremely important. Unfortunately, most sunscreens on the market do not have a photostability label, making them difficult to compare (Diffey et al., 2000; Hojerova et al., 2007; Stanfield et. al., 2010).

Organic UV filters are usually single or multiple aromatic structures, sometimes conjugated with carbon-carbon double bonds and/or carbonyl moieties, able to attenuate the transmission of energetic solar photons. By photons absorption, organic UV filters are transferred to an excited electronic state from which the energy may dissipate after internal conversion into molecular vibration, and further into heat via collisions with surrounding molecules. This absorption is leading to photochemical reactions in these molecules, such as trans-cis transformation, keto-enol tautomerism or the reaction with other UV filters or fragment in product (Tarras-Wahlberg et al., 1999; Herzog et al., 2009; Klocker et al., 2012). There can be reversible and irreversible photoreactions. Only an irreversible change in the chemical structure after irradiation is designed as photounstability (Herzog et al., 2009). Except the photochemical reaction photon absorption can also lead to significant photodegradation of UV filter molecules. Photodegradation reactions may change the physical properties of UV filter (for example the maximum wavelength and absorption coefficient) and lead to formation of adverse photoproducts, which subsequently accumulate on the human skin (Damiani et al., 2007; Gaspar a Campos, 2007; Herzog et al., 2009). The photounstability leads to a loss in absorbance which ultimately translates into reduced photoprotection of the sunscreens (Bonda and Steinberg, 2000; Dondi, 2006).

Photounstability of organic UV filters is attended by formation of reactive intermediates, which can create photooxidation and encourage creation of free radicals. These free radicals, reactive oxygen species (ROS) may not only interact with other co-formulated ingredients of sunscreen products but also with skin constituents such as lipids, proteins and nucleic acids (Pescia et al., 2012). These interactions may lead to the formation of new molecules with unknown toxicological properties (Gaspar et al., 2007). Furthermore, the function of UV filters can be changed not only by the interaction with $\mathrm{UV}$ radiation but also by individual components in sunscreen product and by bad combination of UV filters (Pescia et al., 2012). Maier et al. (2001) conducted an in vitro test and measured the spectral absorbance of 16 sunscreens before and after exposure to solar-simulated radiation. Seven of them products showed wavelength decrease of the UVA protective capacity, whereas the ability to absorb UVB was not affected. Their analysis showed that the behavior of sunscreen products was not predictable from its indiviual ingredients. This means that if the single UV filter is photounstable it does not mean photounstability of the complete sunscreen products (Maier et al., 2001).

At present, there is no validated method for sunscreen photostability evaluation. However, various methods of in vitro evaluation allow with certain measure of accuracy to estimate photoprotective capacities of UV filters or their combinations. Results will not confirm or reject the declared photoprotection during the whole time that the consumer will be exposed to sun; this can be calculated as a multiplied value of SPF and time period (in minutes) of his natural skin protection according to consumer phototype.

In fact, there is plentiful literature on photostability of individual UV filters and final sunscreen products upon UV irradiation where the researchers usually use various solar simulator apparatuss (e.g. Stokes and Diffey, 1999; Herzog et al., 2000; Cambon et al., 2001; Maier et al., 2001, 2005; Serpone et al., 2002; Marrot et al., 2004; Lodén et al., 2011; Dondi et al., 2006; Hojerová et al., 2006; Gaspar and Campos, 2007; Couteau et al., 2007, 2009; Gonzales et al., 2006; Moyal and Fourtanier, 2008; Venditti et al., 2008; Herzog et al., 2009; Scalia et al., 2010; Hojerová et al., 2011). Although the in vivo measurement of photostability is well globaly established by COLIPA (2006), several different in vitro methods have been proposed to assess photostability of sunscreen (Osterwalder and Herzog, 2010). The results of many studies emphasize a fact that evaluation of photostability is very important to guarantee the efficacy of sunscreen products. However, it is very difficult for the consumer to choose the appropriate product, because the photostability of the sunscreen is usually not indicated on the bottle. The researchers' studies, including our experimental results (illustration is shown in Figure 1) showed that sunscreens performance measurement and photoprotection label are still far from perfect.

\section{Conclusion}

The safety of many chemical substances has been questioned during the past decades; it is not surprising that organic UV filters have not escaped this trend. In recent years, the safety and useful- 

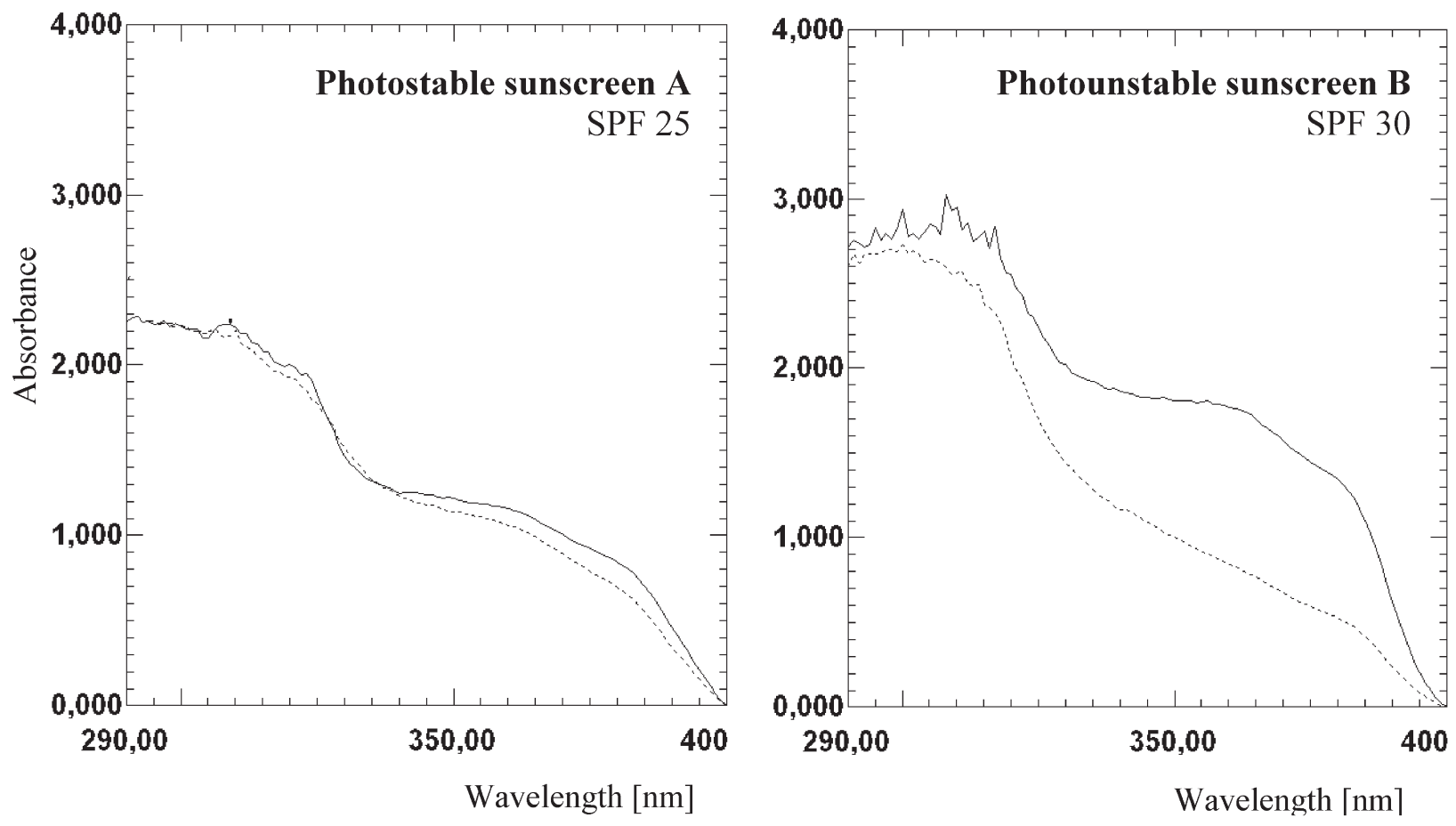

Fig. 1. Absorption spectra of the photostable (A) and photounstable (B) commercial sunscreens before (full line) and after (dotted line) natural sunlight exposure with an adequate dose.

UV filters composition: Sunscreen A: Octocrylene, Butylmethoxydibenzoyl Methane, Homosalate, Phenylbenzimidazole Sulfonic Acid; Sunscreen B: Octocrylene, Homosalate, Butylmethoxydibenzoyl

Methane, Dietylhexyl Butamido Triazone (chemical name of UV filters see in the Table 1). Applied amount: $0.75 \mathrm{mg} / \mathrm{cm}^{2} \pm 5 \%$ of sunscreen.

Substrate: a roughened site $(2 \mu \mathrm{m})$ of the PMMA Plexiglas plate (Schönberg GmbH, Munich, Germany) recommended for photostability testing.

Sunlight exposure: the out-doors exposure during a clear sunny day in late June, 2012 in Bratislava with the assessed sun dose adequate to SPF value indicated on the label.

Instrument: UV/Vis spectrophotometer Shimadzu UV-1800 (wavelength accuracy: $\pm 0.3 \mathrm{~nm}$ ). Absorption spectra are the mean values resulting from three plates; reproducibility within $10 \%$.

(Our experimental unpublished results, 2012).

ness of organic UV filters have been challenged on the basis of the following objections: they may penetrate the skin resulting in systemic exposure, they may degrade under sunlight resulting in toxic degradation products, and they can be potential endocrine disruptors. Most studies agreed with their potential of dermal absorption, estrogenic effects and photounstability. The studies concerning these possible negative effects of UV filters used different methods and different models, so the results are very controversial. Therefore, the validated methods are needed to be sure of sunscreen safety. In any case, taking into account everything discussed in scientific articles and the determination of UV filters safety is a research field with good future prospects.

Assessment of skin absorption and photostability of UV filters are currently paid to begin at our workplace.

\section{References}

Bonda CA, Steinberg DC (2000) Cos. Toil. 115: 37-45.

Cambon M, Castell D, Robert C (2001) Int. J. Cosmet. Sci. 52: $1-11$.

Carou ME, Deguiz ML, Reynoso R, Szwarcfarb B, Carbone S, Meguilevsky JA, Scacchi P, Ponzo OJ (2009) Environ. Toxicol. Pharmacol. 27: 410-414.

COLIPA, 2006. COLIPA Guidelines: International Sun Protection Factor (SPF) test method, 46 p.

Couteau C, Faure A, Fortin J, Paparis E, Coiffard LJM (2007) J. Pharm. Biomed. Anal. 44: 270-273.

Couteau C, El-Boury S, Paparis E, Sébille-Rivain V, Coiffard LJM (2009) Pharm. Dev. Technol. 14: 369-372.

Damiani E, Baschong W, Greci L (2007) J. Photochem. Photobiol. B. 87: 95-104.

Diffey BL, Tanner PR, Matts PJ, Nash JF (2000) J. Am. Acad. Dermatol. 43: 1024-1035.

Dondi D, Albini A, Serpone N (2006) Photochem. Photobiol. Sci. 5: 835-843. 
Durand L, Habran N, Henschel V, Amighi K (2008) Int. J. Cosmet. Sci. 31: 279-292.

EC (2006) European Commission. Of. J. Eur. Comm. L 265/39: $1-5$.

EC (2009) European Commission. Of. J. Eur. Comm. L 342/59: 59-209.

FDA (2011) U.S. Food and Drug Administration. Federal Register 76: 35678-35681.

Felix T, Hall BJ, Brodbelt JS (1998) Anal. Chim. Acta. 371: 195-203.

Gaspar LRM, Campos PMBG (2007) Int. J. Pharm. 343: 181-189.

Giokas DL, Amparo S, Chisvert A (2007) Trends Anal. Chem. 26: 360-374.

Gonzalez H, Farbort A, Larko O, Wennberg AM (2006) Br. J. Dermatol. 154: 337-340.

Guldson B, Wong H, Korsch M, Gomez L, Casey P, McCall M, McCulloch M, Trotter J, Stauber J, Greenoak G (2012) Sci. Total Environ. 420: 313-318.

Hany J, Nagel R (1995) Dtsch. Lebensm. Rundsch. 91: $341-345$.

Herzog B, Wehrle M, Quass K (2009) Photochem. Photobiol. 85: 869-878.

Herzog B, Mongiat S, Deshayes C, Neuhaus M, Sommer K, Mantler A (2000) Int. J. Cosmetic. Sci. 24: 170-185.

Hojerová J, Šovčíková D, Mikula M (2006) J. Pol. Soc. Cosmet. Chem. 9: 11-16.

Hojerová J, Medovčíková A, Mikula M (2007) J. Pol. Soc. Cosmet. Chem. 9: 191-197.

Hojerová J, Boskovičová E (2009). Kozmetika-zdraviekrása (in Slovak). MetroMedia, Bratislava, pp. 354.

Hojerová J, Medovčíkova A, Mikula M (2011) Int. J. Pharm. 408: 27-38.

Chisvert A, León-González Z, Tarazona I, Salvador A, Giokas D (2012) Anal. Chim. Acta 752: 11-29.

Janjua NR, Mogensen B, Andersson AM, Petersen JH, Henriksen M, Skakkebaek NE, Wulf HC (2004) J. Invest. Dermatol. 123: 57-61.

Klocker J, Oelgemöller M, Robertson S, Glass BD (2012) J. Photochem. Photobiol. 13: 91-110.

Kunisue T, Chen Z, Louis GMB, Sundaram R, Hediger M, Sun L, Kannan K (2012) Environ. Sci. Technol. 46: 4624-4632.

Lodén M, Beitner H, Gonzalez H, Edström DW, Åkerström U, Austad J, Buraczewska-Norin I, Matsson M, Wulf HC (2011) Br. J. Dermatol. 165: 255-260.

Ma RS, Cotton B, Lichtensteiger W, Schlumpf M (2003) Toxicol. Sci. 74: 43-50.

Maier H, Schauberger G., Brunnhofer K, Hönigsmann H (2001) J. Invest. Dermatol. 117: 256-262.
Maier H, Schauberger G, Martincigh BS, Brunnhofer K, Honigsmann H (2005) Photodermatol. Photoimmunol. Photomed. 21: 84-92.

Marrot L, Belaidi JP, Lejeune F, Meunier JR, Asselineau D, Bernerd F (2004) Br. J. Dermatol. 151: 1234-1244.

Moyal DD, Fourtanier, AM (2008) J. Am. Acad. Dermatol. 58: $149-154$.

Nashev LG, Schuster D, Laggner Ch, Sodha S, Langer T, Wolber G, Odermatt A (2010) Biochem. Pharmacol. 79: 1189-1199.

Osterwalder U, Herzog B (2010) Photochem. Photobiol. Sci. 9: 470-481.

Pescia AC, Astolfi P, Puglia C, Bonina F, Perrotta R, Herzog B, Damiani E (2012) Int. J. Pharm. 427: $217-223$

SCCS (2012) E.U. Scientific Committee on Consumer Safety. SCCS/1501/12: 1-133.

Scalia S, Mezzena M, Ramaccini D (2011) Skin. Pharmacol. Physiol. 24: 182-189.

Scalia S, Mezzena M, Bianchi, A (2010) Int. J. Cosmet. Sci. 32: 55-64.

Serpone N, Salinaro A, Emeline V, Horikoshi S, Hidaka H, Zhao JC (2002) Photochem. Photobiol. Sci. 1: 970-981.

Schlumpf M, Cotton B, Conscience M, Haller V, Steinmann B, Lichtensteiger W (2001) Environ. Health. Perspect. 109: 239-244.

Schlumpf M, Kypke K, Birchler M, Durrer S et al. (2008) Chimie 62: 345-351.

Schreurs R, Sonneveld E, Jansen JHJ, van der Burg B (2005) Toxicol. Sci. 83: 264-272.

Schreurs R, Lanser P, Seinen W, van der Burg B (2002) Arch. Toxicol. 76: 257-261.

Stanfield J, Osterwalder U, Herzog B (2010) Photochem. Photobiol. Sci. 9: 489-494.

Stokes R, Diffey BL (1999) Int. J. Cosmet. Sci. 21: 241-251.

Tarras-Wahlberg N, Stenhagen G, Larko O, Rosen A, Wennberg AM, Wennerstrom OJ (1999) Invest. Dermatol. 113: 547-553.

Toutiou E, Godin B (2008) Cl. Dermatol. 26: 375-379.

Venditti E, Spadoni T, Tiano L, Astolfi P, Greci L, Littarru GP, Damiani E (2008) Free Radical Biol. Med. 45: 345-354.

WHO (2006) Environmental Health Criteria 235: Dermal Absorption. World Health Organization Press, Geneva, pp. 197. 